\title{
Faculty Perceptions of Social Media as a Teaching and Learning Tool
}

\author{
Laila Al-Sharqi, Ibrahim Kutbi, Khairudin Hashim \\ Center for Strategic Studies, King Abdulaziz University, Jeddah, Saudi Arabia \\ \{lzayan, ikutbi \& khashim\}@kau.edu.sa
}

\begin{abstract}
Social media has become pervasive. Some see it as a new media for enhancing the teaching and learning environment. It is rich in tools which can help enhance interaction, discussion and sharing of learning resources. This study investigates King Abdulziz University (KAU) instructors' perceptions of social media as a teaching and learning tool. Data were collected using a specially designed survey during the academic year 2013/2014. The sample size was 507 instructors of different ages and genders representing various KAU colleges. The results indicate that a subset of KAU instructors are using social media tools in their teaching and have the desire to integrate social media as a tool in their teaching at university. Survey outcome signifies prevailing interest and positive potential in adoption of social media into the teaching and learning environment. The paper also reports gender significant differences on preferred social media tools and purposes of social media usage. The findings support the advantages of social media in teaching and learning and do not indicate any obvious disadvantages. They include identification of dominant perceptions pertaining to advantages and disadvantages of social media in teaching and learning. These can help discern possible issues relating to using social media as a teaching and learning tool.
\end{abstract}

Index Terms - Social media, teaching and learning, instructor perception, perception difference, gender difference

\section{Introduction}

Widespread use of social media as a communication tool has convinced some to consider it as a new media for enhancing the teaching and learning environment. It has impacted the social fabric of our society, changing the nature of social relationships. New technologies help facilitate and provide flexibility in communicating and sharing of resources. Collaboration is the cornerstone of social learning. Through collaboration facilitated by instructors, students engage in problem solving endeavors. As such, the role of a teacher is not just to define, generate or assign content but it is to help learners build learning paths and make connections with existing and new knowledge resources [1].

Excessive use of social media tools by college students has led to debate over whether or not it has changed the very shape and structure of students' social behavior and academic practices, and has thus caused leading educators to redefine their understanding of interpersonal communication and study dynamics [2]. As such, it is pertinent to seek the views of instructors pertaining to use of social media as a teaching and learning tool.

Students use social media tools for many purposes such as access to information, group discussion, resource sharing and entertainment [3]. This has generated speculation on their use and possible positive and negative implications, in both the short and the long terms. As several studies demonstrate, social media interaction could have positive and negative effects on students. They can provide flexibility in learning, stimulate innovative ideas, and increase interpersonal relationships among students and instructors. These tools, however, can have negative impacts on students as they might distract their attention from the learning process, reduce their physical social interaction and be potentially addictive.

Although some studies have investigated the impact of social media on instructors, few have focused on Saudi Arabia. Hence, this study should contribute valuable findings. Its purpose is to explore the impact of social media on instructors at King Abdulaziz University (KAU). This quantitative study focuses on the common factors affecting KAU instructors' preferences and perceptions of the impact of social media on teaching and learning. A research questionnaire was designed to determine the factors that may affect instructors. Through analysis of the data, the study attempts to detect the positive and negative impacts on preferences and perceptions; and to identify key themes and trends that can be used as a foundation for more in-depth research.

The main contribution of the study lies in identifying instructors' usage, preferences and perceptions of social media as a teaching and learning tool which can help in adoption of social media tools in the teaching and learning context. Given the present limitation of available data on instructors' use of social media at the university level, the data gathered provide valuable source of information, as they offer a deeper insight into the academic community's association with the new media.

\section{Literature Review}

A survey [4] done to explore perceptions of faculty and students on the use of social media in higher education revealed that faculty and students perceive social media as fulfilling an important role in extending learning beyond the classroom, triggering students to use new technology, giving the students an opportunity to reflect on their learning and; facilitating and enhancing students' learning.

A study [5] exploring the perceptions of university faculty members for using social media in formal and informal learning indicated that most of the studied population used

* This work is supported by King Abdulaziz University. 
Facebook for personal communication and LinkedIn for professional purposes. It also found that academic activities using social media were designed to be informal reinforcements to classroom teaching rather than conventional assessment tools.

Another study [6] conducted on assessing use of social media in education indicated that the majority of instructors surveyed have used social media in classes. However, with the exception of using the social medium of online forums, videosharing sites and Facebook, participants, in general, did not want to use social media for instructional purposes.

Presently, most college students are exposed to many types of social media on a daily basis. Abdelraheem [7] investigated undergraduate students' use of social networks sites (SNSs) and its relation to gender, grade point average (GPA) and other variables. Analysis of responses of 120 students revealed that students use these sites for social purposes more than academic ones. Alshareef [8] examined the effects of Web 2.0 and social networks on students' performance in online education in KAU. Using data from 100 students obtained through an electronic questionnaire, the study found a significant positive impact of social learning on the students' education compared with traditional teaching.

Liu [9] studied students' use, attitudes and perceptions of 16 different social media tools through an online questionnaire involving 221 students. The top four reasons that prompted students' use of social media tools were found to be social engagement $(85 \%)$, direct communications (56\%), speed of feedback/results (48\%), and relationship building (47\%); less than $10 \%$ used social media tools for academic purposes.

Junco and his co-researchers [2] studied the effect of using Twitter for various types of academic discussion on the engagement and grades of college students. The study examined 125 students (70 in the experimental group and 55 in the control group) using a 19-item scale selected from the National Survey of Student Engagement (NSSE). The authors found that Twitter can motivate both students and faculty's engagement in non-traditional learning activities. In the same vein, Ellison, Steinfield and Lampe [10] asserted that Facebook can facilitate college students' academic learning objectives through instructor-to-student and student-to-student course communication e.g. responding to questions and managing out-of-class projects.

\section{Research Methodology}

This study used both primary and secondary sources of data. The secondary data were from the literature review described above. The primary data were collected through questionnaires administered to randomly selected respondents representing a sample of university instructors from various academic disciplines of KAU. The research team designed and fine-tuned the survey instrument and conducted a workshop to obtain the opinion of administrators, instructors and students on which topics to include.

The survey included a total of 507 instructors who were randomly selected from various colleges of KAU. The target respondents represented a homogeneous mix (male/female), different age groups and disciplines to sufficiently preserve optimal diversity within the collected data required for subsequent analysis.

The questionnaire was pre-tested and revised by several senior university faculty members, who, specializing in sampling and questionnaire design, made modifications to enhance clarity. The questionnaire was then pilot tested, using a version that contained the questions in both English and Arabic languages, to provide a survey questionnaire in dual languages for ease of understanding. Based on the target numbers, copies of the questionnaire were then distributed.

Completed responses were collated and submitted to coordinators. A statistician was engaged to ensure that processing of data was done properly. Data were coded and processed into SPSS, a statistical package system. Results were analyzed and summarized, in order to draw conclusions and make recommendations.

The raw data from the returned questionnaires were then coded and entered into the statistical system. The data were explored both for their descriptive statistics (i.e. calculation of percentage distributions, frequency distributions, calculations of averages, and coefficient of variation) and inferential statistics (i.e. level of significance, t-test, z-test, ANOVA, correlation and regression and classification analysis). Cronbach's Alpha was also used to provide indications of internal consistency.

The questionnaire was divided into four parts. In the first part, instructors were requested to respond to general and demographic questions about their gender, age, and field of specialization. Next, respondents were asked about their level of association with the Internet and social media use. The second part provided more specific questions on the types of social media respondents use, the purpose for which they use social media and their preference on the integration of social media in teaching and learning. The third part addressed on questions related to respondents' perspectives on the benefits of social media use in teaching and learning while the fourth part focused on their views on the negative aspects related to social media use in teaching and learning.

\section{Results and Discussion}

A total 507 instructors participated in the survey on social media as a teaching and learning tool. The total sample size meant an acceptable error of $\pm 4 \%$ at 95 percent confidence level for the university population.

In investigating significant difference, the Pearson Chisquare test of independence is used. If chi-square results are significant, post-hoc analysis is then conducted for identifying significant differences at the 0.05 level through column proportions z-tests approach (adjust p-values for multiple comparisons Bonferroni method).

\section{A. Sample Breakdown based on Demographic Factors}

Table 1 shows the sample breakdown according to the demographic variables considered. There were 61 percent male and 39 percent female instructors. The dominant age 
group for instructors is the ' 30 to less than 40 years' category. The dominant teaching experience is the ' 15 years or more' category while the dominant academic rank is the 'assistant professor' category. The sampled cohorts provide a consistent representative sample of the ratios of the overall KAU instructor population.

TABLE 1. Sample breakdown based on demographic factors

\begin{tabular}{|c|c|c|c|}
\hline & Category & Count & $\%$ \\
\hline \multirow{2}{*}{ Gender } & Male & 309 & 60.9 \\
\hline & Female & 198 & 39.1 \\
\hline \multirow{4}{*}{ Age Group } & less than 30 years old & 63 & 12.4 \\
\hline & from 30 to less than 40 & 167 & 32.9 \\
\hline & from 40 to less than 50 & 154 & 30.4 \\
\hline & 50 or above & 123 & 24.3 \\
\hline \multirow{4}{*}{$\begin{array}{l}\text { Teaching } \\
\text { Experience }\end{array}$} & less than 5 years & 105 & 20.7 \\
\hline & from 5 to less than 10 & 117 & 23.1 \\
\hline & from 10 to less than 15 & 83 & 16.4 \\
\hline & 15 years or more & 202 & 39.8 \\
\hline \multirow{6}{*}{$\begin{array}{l}\text { Academic } \\
\text { Rank }\end{array}$} & Full Professor & 87 & 17.2 \\
\hline & Associate Professor & 100 & 19.7 \\
\hline & Assistant Professor & 155 & 30.6 \\
\hline & Lecturer & 112 & 22.1 \\
\hline & Demonstrator & 53 & 10.5 \\
\hline & Total & 507 & 100.0 \\
\hline
\end{tabular}

\section{B. KAU Instructors' Background on the Internet and Social Media}

The survey included some questions designed to provide information about KAU instructors' background in using the Internet and social media. These questions are shown in Table 2 , together with their corresponding responses. The responses indicated that KAU instructors are familiar with and are immersed in the Internet and social media use.

The major category for using Internet per week is the ' 15 hours or more' category and the majority of instructors use Internet from 10 hours or more per week. Approximately $90 \%$ of instructors have a personal social media account. On the average number of hours instructors spend using social media per week, the major category is the 'less than 3 hours' category. The majority of instructors have been using social media tools for more than 3 years. These findings reflect the maturity of KAU's instructors regarding use of the Internet and social media.

TABLE 2. KAU instructors' background in Internet and social media

\begin{tabular}{|c|c|c|c|}
\hline & & Count & $\%$ \\
\hline \multirow{4}{*}{$\begin{array}{l}\text { On average how many } \\
\text { hours do you } \\
\text { using indend } \\
\text { week? }\end{array}$} & less than 5 & 47 & $9.3 \%$ \\
\hline & from 5 to less than 10 & 127 & $25.0 \%$ \\
\hline & from 10 to less than 15 & 123 & $24.3 \%$ \\
\hline & 15 hours or more & 210 & $41.4 \%$ \\
\hline \multirow{2}{*}{$\begin{array}{l}\text { Do you currently have } \\
\text { a personal social media } \\
\text { account? }\end{array}$} & Yes & 457 & $90.1 \%$ \\
\hline & No & 50 & $9.9 \%$ \\
\hline \multirow{5}{*}{$\begin{array}{l}\text { On average how many } \\
\text { hours do you spend } \\
\text { using social media per } \\
\text { week? }\end{array}$} & none & 50 & $9.9 \%$ \\
\hline & less than 3 & 133 & $26.2 \%$ \\
\hline & from 3 to less than 6 & 118 & $23.3 \%$ \\
\hline & from 6 to less than 10 & 112 & $22.1 \%$ \\
\hline & 10 hours or more & 94 & $18.5 \%$ \\
\hline \multirow{4}{*}{$\begin{array}{l}\text { Using social media } \\
\text { for? }\end{array}$} & none & 50 & $9.9 \%$ \\
\hline & less than 1 year & 34 & $6.7 \%$ \\
\hline & $1-3$ years & 166 & $32.7 \%$ \\
\hline & more than 3 years & 257 & $50.7 \%$ \\
\hline \multirow{3}{*}{$\begin{array}{l}\text { Which language do } \\
\text { you prefer when you } \\
\text { visit social media? }\end{array}$} & English & 117 & $23.4 \%$ \\
\hline & Arabic & 122 & $24.4 \%$ \\
\hline & Both & 260 & $52.1 \%$ \\
\hline
\end{tabular}

On the preferred language when visiting or using social media, a marginal majority selected category 'Both' (English and Arabic languages). This indicates that they are marginally bilingual in their use of social media. Table 3 provides the breakdown in responses pertaining to the use of social media in teaching and learning; and preference to integrate social media into the teaching and learning environment. On the current use of social media in teaching and learning, 31 percent of instructors are using social media tools in one course or more of their teaching at university.

In response to the question on whether instructors would like to integrate social media as a tool in their teaching, a high majority $(72 \%)$ responded affirmatively. However, the findings of the study [6] conducted state that instructors surveyed were mostly opposed to using social media for instructional purposes. 
TABLE 3. KAU instructors' use of social media in courses and preference to integrate

\begin{tabular}{|c|c|c|c|}
\hline & & Count & $\%$ \\
\hline \multirow{4}{*}{$\begin{array}{l}\text { In how many of courses in } \\
\text { your teaching at this } \\
\text { university are you using } \\
\text { social media? }\end{array}$} & none & 349 & $69.4 \%$ \\
\hline & one course & 118 & $23.5 \%$ \\
\hline & Two courses & 9 & $1.8 \%$ \\
\hline & Three courses or more & 27 & $5.4 \%$ \\
\hline \multirow{3}{*}{$\begin{array}{l}\text { Would you like to } \\
\text { integrate social media as a } \\
\text { tool in your teaching? }\end{array}$} & Yes & 360 & $71.6 \%$ \\
\hline & No & 71 & $14.1 \%$ \\
\hline & I don't know & 72 & $14.3 \%$ \\
\hline
\end{tabular}

\section{KAU Instructors' Preferred Social Media Tools}

We sought to answer the questions related to social media tools most commonly used by instructors. The breakdown in social media tool usage is given in Figure 1. The survey question was of multiple response type. Category 'Facebook' is topmost followed by category 'YouTube' and then category 'Twitter'. The finding pertaining to Facebook is in line with the finding of a study [5] done by Chen and Bryer in which Facebook was identified as one of the most popular social media tools used by instructors.

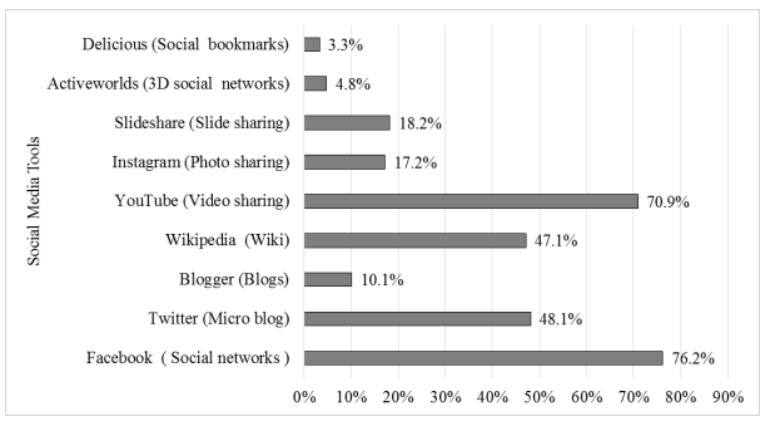

Figure 1. Breakdown in social media tool usage

Gender breakdown and significant differences on social media tools: The gender breakdown in social media tool usage is given in Figure 2. Amongst the gender groups, the top two categories are 'Facebook' and 'YouTube'. For the male group, category 'Facebook' is topmost while for the female group category 'YouTube' is topmost. For the third position category, the male group is represented by Twitter while for the female group it is Wikipedia. Some differences in the proportion of responses are witnessed. In the case of Facebook, the male instructors' proportion is 83 percent while the female instructors' proportion is 64 percent. These findings are in contrast with findings of a study [11] on adoption of social network which state that women in the U.S. are more skewed to Facebook than men by about 10 percentage points. Wikipedia has higher preference level compared to Twitter for the female instructors group, unlike the male group. As Wikipedia is an encyclopaedic facility related to teaching and learning, this signifies that female instructors have stronger inclination towards using social media for teaching and learning.

The value of the Pearson Chi-Square relating to the social media tools of Figure 2 is significant at $p$ less than 0.01 . Hence, there exists a strong association between the social media tools and gender. Post-hoc analysis indicates that there are greater proportions of responses by the male instructors than the female instructors in the 'Facebook', 'Blogger', 'Flickr' and Secondlife' categories and that the differences are significant at the 0.05 level. For Wikipedia, YouTube, Instagram and Slideshare tools, there are greater proportions of responses by the female instructors than the male instructors and that these differences are significant at the 0.05 level.

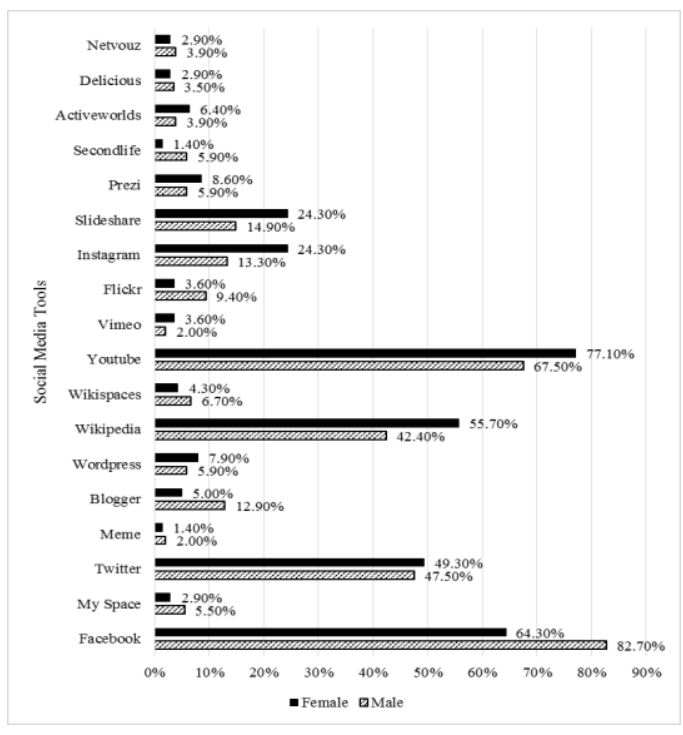

Figure 2. Gender breakdown in social media tool usage

\section{Purposes on Usage of Social Media}

Figure 3 shows the breakdown for purposes of social media tool usage. It shows the distribution of the instructor sample as per the most common purposes. The survey question was of multiple response type. The figure reveals that instructors use social media tools for a blend of academic and non-academic purposes. Category 'Searching for information' is topmost followed by category 'Learning' and then category 'Exchanging ideas'. The categories of 'Searching for information' and 'Exchange ideas' are identified with knowledge building and the domain of learning.

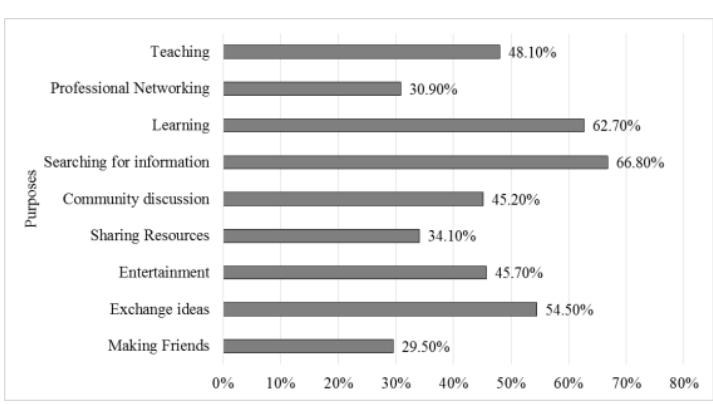

Figure 3. Breakdown for purposes of social media tool usage 
Gender Breakdown and Significant differences on Purposes of Social Media Usage: Figure 4 shows the gender breakdown for purposes of social media tool usage. It shows the distribution of instructors sample as per the most common purposes. Amongst the gender groups, the top two categories are 'Searching for information' followed by 'Learning'. The female group has a higher proportion for categories 'Searching for information' and 'Learning'. This indicates that the female group leans towards learning more than the male group. For the third position category, the male group is represented by 'Exchange ideas' category while for the female group it is the 'Entertainment' category. The category 'Exchange ideas' is identified with knowledge building and the domain of learning. It is interesting to note that males and females have almost the same proportion for category 'Making friends' which is in contrast with the outcome of a study [12] conducted by Mazman and Usluel which states that males are more dominant in using social media for making new contacts compared to females.

Another point to note is that 46 percent of male instructors selected category 'Teaching' while a majority of 53 percent of females selected the same. This reflects a stronger usage level of social media use in teaching by the female group compared to the males.

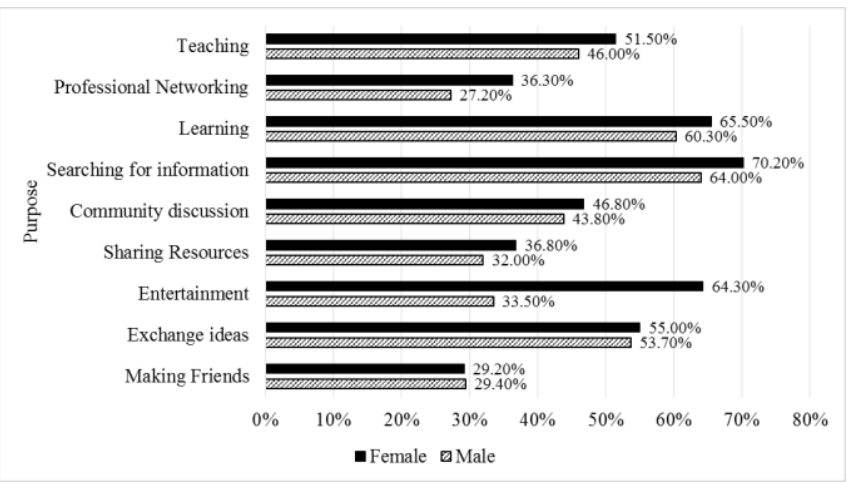

Figure 4. Gender breakdown for purposes of social media tool usage

The value of the Pearson Chi-Square relating to the categories of Figure 4 is significant at $p$ less than 0.01. Hence, there exists a strong association between purposes of social media usage and gender. Post-hoc analysis indicates that the proportions for the female group is greater than the proportions for the male group for categories of 'Entertainment' and 'Professional networking' and that these differences are significant at the 0.05 level.

\section{E. Evaluating KAU Instructors' Perceptions of Social \\ Media Usage in Teaching and Learning}

The remaining portion of the questionnaire was designed to investigate instructors' perceptions of the following: a) rating a set of statements as benefits (advantages) that encourages the use of social media for teaching and learning; and b) rating a set of statements as problems (disadvantages) that prevents instructors from using social media for teaching and learning. Data regarding perceptions of the advantages and disadvantages of using social media for teaching and learning were collected using a five-point Likert level of agreement scale. The variation in opinions is low based on the coefficient of variation for all statements. This indicates that instructors are aware of the advantages and disadvantages of using social media in teaching and learning.

Table 4 shows the overall rating of responses on the two factors, advantages and disadvantages. Based on Table 5 which provides the mean and corresponding agreement attitude, the mean value for factor advantages is of attitude 'Agree' while the mean value for factor disadvantages is of attitude 'Unsure'. This indicates that instructors agree with the advantages but are unsure of the disadvantages.

TABLE 4. Mean distribution over factors for advantages and disadvantages

\begin{tabular}{|l|l|}
\hline Study factor & Mean \\
\hline $\begin{array}{l}\text { Advantages of using Social Media Networks in teaching and } \\
\text { learning }\end{array}$ & 3.88 \\
\hline $\begin{array}{l}\text { Disadvantages of using Social Media Networks in teaching and } \\
\text { learning }\end{array}$ & 3.25 \\
\hline
\end{tabular}

TABLE 5. Mean and corresponding agreement attitude

\begin{tabular}{|l|l|}
\hline Value of weighted mean & Agreement attitude \\
\hline From 1 to 1.79 & Strongly Disagree \\
\hline From 1.80 to 2.59 & Disagree \\
\hline From 2.60 to 3.39 & Unsure \\
\hline From 3.40 to 4.19 & Agree \\
\hline From 4.20 to 5 & Strongly Agree \\
\hline
\end{tabular}

Cronbach's alpha $(\alpha)$ was used to test for reliability of results. The study factors are reliable as shown in Table 6 by Cronbach's alpha values of greater than 90 percent.

TABLE 6. Cronbach's alpha for the study factors

\begin{tabular}{|l|c|c|}
\hline Study factor & No. of items & Cronbach's alpha \\
\hline $\begin{array}{l}\text { Advantages of using social } \\
\text { media in teaching and learning }\end{array}$ & 17 & 0.94 \\
\hline $\begin{array}{l}\text { Disadvantages of using social } \\
\text { media in teaching and learning }\end{array}$ & 19 & 0.91 \\
\hline
\end{tabular}

1) Investigation of Dominant Issues on Advantages of Using Social Media in Teaching and Learning: Out of the items on advantages, we selected the top five perceptions by mean values. This helps to identify support factors in using social media as a teaching and learning tool. The summary for perceptions of advantages is given in Table 7.

Instructors believe that use of social media in teaching and learning helps in exchange and co-creation of knowledge, facilitate instructor-students communication, be useful in updating students with new resources, speed up the process of providing feedback and results to students; and facilitate sharing ideas with other educators. 
TABLE 7. Top 5 perceptions of possible benefits (advantages) on the use of social media in teaching and learning

\begin{tabular}{|l|c|}
\hline Factor (in descending order) & Mean \\
\hline Help in exchanging and co-creating knowledge & 4.10 \\
\hline Facilitate instructor-students communication & 4.10 \\
\hline Useful in updating students with new resources & 4.03 \\
\hline $\begin{array}{l}\text { Speed up the process of providing feedback/results to } \\
\text { students }\end{array}$ & 3.99 \\
\hline Share ideas with other educators & 3.98 \\
\hline
\end{tabular}

These findings are in line with the findings of the study [4] on the perceived benefits of using social media in higher education. However, the factor on social media facilitating instructor-students communication is in contrast with the findings of the study [6] conducted by Settle and team which state that the instructors surveyed expect the amount of communication to increase but did not expect any increase in the quality of communication.

2) Investigation of Dominant Issues on Disadvantages of Using Social Media in Teaching and Learning: Out of the items on disadvantages, we selected the top five sub-factors by mean values. This helps to highlight potential problems in using social media as a teaching and learning tool. The summary for sub-factors on disadvantages is given in Table 8 .

TABLE 8. Top 5 perceptions of possible problems (disadvantages) on the use of social media in teaching and learning

\begin{tabular}{|l|c|}
\hline Factor (in descending order) & Mean \\
\hline $\begin{array}{l}\text { Create more demand on Internet access facilities for students } \\
\text { in the classroom }\end{array}$ & 3.70 \\
\hline Lack of proper classroom technical support for instructors & 3.55 \\
\hline Increase my addictive potential to media and Internet & 3.53 \\
\hline Require more work and preparation & 3.43 \\
\hline Require formal training & 3.41 \\
\hline
\end{tabular}

It is interesting to note that the top two factors relate to administrative issues i.e. the creation of more demand on Internet access facilities and the lack of technical support for instructors. The emphasis on technical support echoes the concern of instructors in the study [5] conducted by Chen and Bryer which highlighted a strong need for faculty support in terms of adopting new technologies. The third factor highlights concern of addiction to media and Internet. The two remaining factors within the top five list by instructors are 'Require more work and preparation' and 'Require formal training', reflecting concern over increase in workload and need for technical guidance, respectively.

\section{Conclusions}

Instructors are familiar with and use social media. They use different categories of the social media tools for academic and non-academic purposes. They have a positive preference slant towards using social media for teaching and learning with a high majority in response to the question on whether they would like to integrate social media as a tool in their teaching and learning.

On social media tools, category 'Facebook' is topmost followed by category 'YouTube' and then category 'Twitter'. Relating to purposes of social media tool usage, category 'Searching for information' is topmost followed by category 'Learning' and then category 'Exchanging ideas'. The categories of 'Searching for information' and 'Exchange ideas' are identified with knowledge building and the domain of learning. This signifies prevailing interest and positive potential in adoption of social media into the teaching and learning environment.

Instructors agree on the advantages of social media as a teaching and learning tool but are unsure of the disadvantages. The study captured the dominant positive and negative perceptions of social media use in teaching and learning. These findings can help identify possible strategies to mitigate concerns identified by the instructors.

\section{References}

[1] T. Anderson, and J. Dron, "Three generations of distance education pedagogy," International Review of Research in Open and Distance Learning, vol. 12, no. 3 pp. 80-97, March 2011.

[2] R. Junco, D. Merson, and D. Salter, "The effect of gender, ethnicity, and income on college students' use of communication. cyberpsychology," Behavior and Social Networking, vol. 13, no. 6, 2010.

[3] Q. Wang, W. Chen, and Y. Liang, "The effects of social media on college students," (MBA Student Scholarship), Johnson \& Wales University, 2011. Retrieved fromhttp://scholarsarchive.jwu.edu/cgi/viewcontent.cgi?article $=1004 \& \mathrm{c}$ ontext=mba_student.

[4] G. Zgheib, and N. Dabbagh, "Exploring perceptions of faculty and students' use of social media in higher education," 2013. Retrieved from http://www.aect.org/pdf/proceedings13/2013/13_39.pdf.

[5] B. Chen, and T. Bryer, "Investigating instructional strategies for using social media in formal and informal learning," The International Review of Research in Open and Distance Learning, vol. 13, no. 1, 2012.

[6] Q. Settle, R. Telg, T. Irani, E. Rhoades and T. Rutherford, "Instructors' social media use and preferences in agriculture classes", NACTA Journal, vol. 55, no. 2, pp. 98-83, 2011.

[7] A. Y. Abdelraheem, "University students' use of social networks sites and their relation with some variables", Paper presented at the WEI International Academic Conference, Antalya, Turkey, 2013 [14-16 January 2013].

[8] M. Alshareef, "Evaluate student satisfaction for social learning network at King Abdulaziz University", Advances in Internet of Things, vol. 3, pp. 41-44, 2013.

[9] Y. Liu, "Social media tools as a learning resource", Journal of Educational Technology Development and Exchange, vol. 3, no. 1, pp. 101-114, 2010.

[10] N. Ellison, C. Steinfield, and C. Lampe, "The benefits of Facebook "friends": Social capital and college students' use of online social network sites", Journal of Computer-Mediated Communication, vol. 12, no. 4, pp. 1143-1168, 2007.

[11] T. Guimaraes, "Revealed: The demographic trends for every social network", 2014. Retrieved from http://www.businessinsider.com/2014social-media-demographics-update-2014-9.

[12] S. G. Mazman, and Y. K. Usluel, "Gender differences in using social networks", Turkish Online Journal of Educational Technology, vol. 10, no. 2, pp.133-139, 2011. 